\title{
Влияние различных факторов на необменную сорбцию аминокислот анионообменниками
}

\author{
(C) 2021 Хохлова О.Н., Трошина П.В., Быковская А.И., \\ Каширцева Е.Р., Хохлов В.Ю.
}

Воронежский государственный университет, Воронеж

Поступила в редакцию 5.05.2021 г.

DOI: $10.17308 /$ sorpchrom.2021.21/3632

С целью обзора ряда действующих факторов при необменной сорбции аминокислот ионообменниками исследовано влияние природы и ионной формы сорбента, сорбата и растворителя, условий проведения сорбции - температуры и диапазона концентраций на величину поглощения глицина и фенилаланина анионообменником АВ-17-2П, сверхсшитым сорбентом MN-150 из водных и спиртовых растворов при температурах 293 и 343 К в концентрационных диапазонах, ограниченных растворимостью аминокислот.

Установлено, что изменение ионной формы анионообменника АВ-17-2П с хлоридной на нитратную приводит к уменьшению количества поглощенного фенилаланина за счет изменения размерных и гидратационных характеристик противоиона, приводящих к ослаблению полярных взаимодействий в фазе сорбента при необменном закреплении аминокислот. Использование неводного растворителя, например, этилового спирта приводит к уменьшению растворимости аминокислот, а, следовательно, рабочего диапазона концентраций, уменьшению набухания анионообменника, что и обусловливает меньшее количество поглощаемой аминокислоты.

К существенному улучшению поглощения фенилаланина приводит использование сверхсшитого сорбента или повышение температуры. В первом случае усиливаются гидрофобные взаимодействия между ароматическим радикалом фенилаланина и матрицей сорбента. Во втором случае разнонаправленное действие температурного фактора на сорбат, сорбент и связи между ними в итоге приводит к увеличению сорбции за счет улучшения набухания ионообменника. Хорошая растворимость глицина позволяет исследовать поглощение этой аминокислоты в широком интервале концентраций. По виду полученной изотермы с учетом характеристик ионообменника установлено формирование в сорбенте последовательно первого и второго слоя вещества на сорбционных центрах «функциональная группа-противоион».

Ключевые слова: анионообменник, глицин, фенилаланин, необменная сорбция.

\section{Введение}

Величина поглощения сорбата сорбентом определяется рядом факторов, варьируя которые можно обоснованно выбирать системы с заданными характеристиками для решения конкретных практических задач. В большинстве случаев авторами рассматривается действие ограниченного набора параметров процесса, однако представляет интерес рассмотрение комплекса свойств и условий для сравнения характеристик сорбции. С целью обзора ряда действующих факторов при необменной сорбции аминокислот ионообменниками исследовано влияние природы и ионной формы сорбента, сорбата и растворителя, условий проведения сорбции - температуры и диапазона концентраций на величину поглощения глицина и фенилаланина анионообменником АВ-17-2П, сверхсшитым сорбентом MN-150 из водных и спиртовых растворов при 293 и 343 К в концен- 
трационных диапазонах, ограниченных растворимостью аминокислот.

\section{Экспериментальная часть}

В работе использованы два сорбента на основе стиролдивинилбензола анионообменник АВ-17-2П и сверхсшитый MN-150 в хлоридной форме, имеющие анионообменные группы (четвертичный и третичный азот соответственно) и различное содержание сшивающего агента (2 и 150\% соответственно), две аминокислоты в виде биполярных ионов глицин и фенилаланин, первая из которых является простейшей, а строение второй отличается наличием бензольного кольца в качестве бокового радикала, два растворителя вода и этиловый спирт, отличающиеся полярностью (с диэлектрической проницаемостью 81 и 25 , соответственно). Рассмотрение сочетаний компонентов со свойствами, изменяющими соотношение полярных и гидрофобных взаимодействий в сорбционной системе позволит выявить наиболее влияющие из них на величину сорбции.

Равновесие в исследуемых сорбционных системах изучено в статических условиях методом переменных концентраций в широком диапазоне для глицина (0.005-1.5 моль/дм $\left.{ }^{3}\right)$ и ограниченном растворимостью для фенилаланина (0.005-0.05 моль/дм³). Для выявления влияния температурного фактора сорбцию проводили при 293 и 343 К. Концентрацию в равновесных растворах определяли спектрофотометрически при 257 нм для фенилаланина и фотометрически при 670 нм для глицина с предварительным переведением в медный комплекс. Содержание аминокислот в сорбенте находили по разности концентраций в растворе до и после сорбции с учетом объема и массы контактирующих фаз.

\section{Обсуждение результатов}

В работе исследованы следующие системы:
«АВ-17-2П в хлоридной-форме + водный раствор фенилаланина» при 293 К (Система I)

«АВ-17-2П в нитратной ионной форме + водный раствор фенилаланина» (Система II)

«АВ-17-2П в хлоридной-форме + спиртовый раствор фенилаланина» (Система III),

«АВ-17-2П в хлоридной-форме + водный раствор фенилаланина» при $343 \mathrm{~K}$ (Система IV),

«MN-150 в хлоридной-форме + водный раствор фенилаланина»(Система V), «АВ-17-2П в хлоридной-форме + водный раствор глицина» (Система VI).

В качестве системы сравнения выбрана Система I «анионообменник AB-172П в хлор-форме + водный раствор фенилаланина» при 293 К, поскольку сорбат и сорбент имеют как полярные, так и гидрофобные структурные элементы, позволяющие закрепляться аминокислоте в ионообменнике реализуя оба типа взаимодействий, а условия сорбции (растворитель и температура) являются наиболее простыми для практического осуществления.

Изотермы сорбции в рассматриваемых системах представлены на рис. 1. Как видно из рисунка, все изотермы не имеют перегибов, что свидетельствует об отсутствии смены механизма сорбции независимо от стартового состава системы.

Как известно $[1,2]$, закрепление аминокислот в фазе ионообменников при необменном поглощении происходит за счет полярных и гидрофобных взаимодействий - кулоновского притяжения противоположно заряженных противоиона анионообменника $\left(\mathrm{Cl}^{-}\right.$или $\left.\mathrm{NO}_{3}{ }^{-}\right)$ и функциональной группы аминокислоты $\left(-\mathrm{NH}_{3}{ }^{+}\right)$и формирования водородных связей между их гидратными оболочками, а также за счет гидрофобных взаимодействий радикала сорбата с матрицей сорбента. 


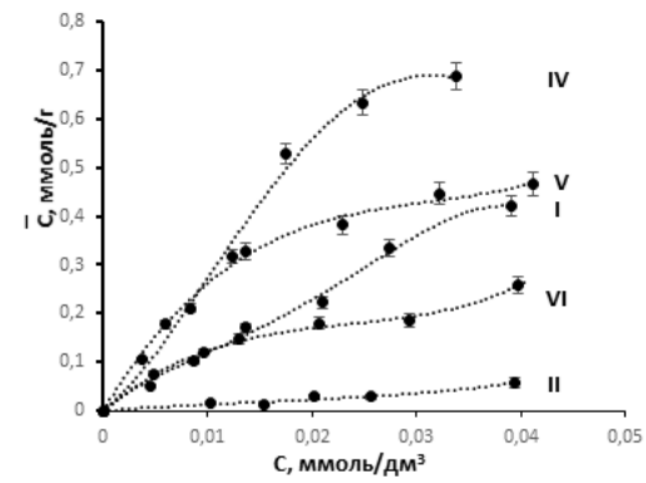

Рис. 1. Изотермы сорбции аминокислот в исследуемых системах (обозначения в тексте).

Fig. 1. Sorption isotherms of amino acids in the studied systems (designations are given)

Изменение ионной формы анионообменника АB-17-2П с хлоридной на нитратную приводит к уменьшению количества поглощенного фенилаланина, что связано с тем, что нитрат-ион имеет большие размеры и отрицательную гидратацию по сравнению с хлоридом, что приводит к ослаблению кулоновского притяжения противоположно заряженных структурных элементов сорбата и сорбента, а также образованию более рыхлой сетки водородных связей между этими элементами [1].

Использование этилового спирта в качестве растворителя уменьшает растворимость аминокислоты [3], а, следовательно, рабочий диапазон концентраций. При этом анионообменник АВ-17$2 П$ меньше набухает в менее полярном спирте, что и обусловливает меньшее количество поглощаемой аминокислоты. Кроме того, происходит частичное перераспределение полярных сил закрепления в пользу гидрофобных, поскольку молекула этилового спирта более крупная и гидрофобная $(\varepsilon=25)$ по сравнению с молекулой воды $(\varepsilon=81)$, поэтому экранирует и ослабляет ион-дипольные взаимодействия противоиона анионообменника и полярной группы аминокислоты.

Изменение природы сорбента и использование сверхсшитого MN-150 приводит к значительному росту сорбции. При повышении процента сшивки более чем на порядок приводит к существен- ному увеличению доли гидрофобной составляющей при закреплении фенилаланина. Увеличение сорбции происходит, не смотря на наличие более слабых функциональных групп в фазе сорбента $\mathrm{MN}-150$ по сравнению с анионитом AB17-2П, т.е. при меньшем количестве диссоциированных сорбционных центров, необходимых для закрепления аминокислоты с помощью полярных сил.

К существенному улучшению поглощения фенилаланина на анионообменнике АВ-17-2П приводит изменение температурного фактора. Повышение температуры ведет к увеличению констант ионизации карбоксильных и аминогрупп аминокислоты [4], но не приводит к изменению ионной формы исследуемых аминокислот, а, следовательно, и изменению типа взаимодействий в фазе сорбента. Однако при повышении температуры усиливается тепловое движение, что способствует частичному разрыву водородных связей [5] и ослаблению гидрофобных взаимодействий [6], что уменьшает количество необменно поглощенного вещества. С другой стороны, усиливается набухание ионообменников, что способствует улучшению необменного поглощения [7]. В рассматриваемом случае последний фактор доминирует по сравнению с разупорядочивающим действием теплового движения (рис. 2). 


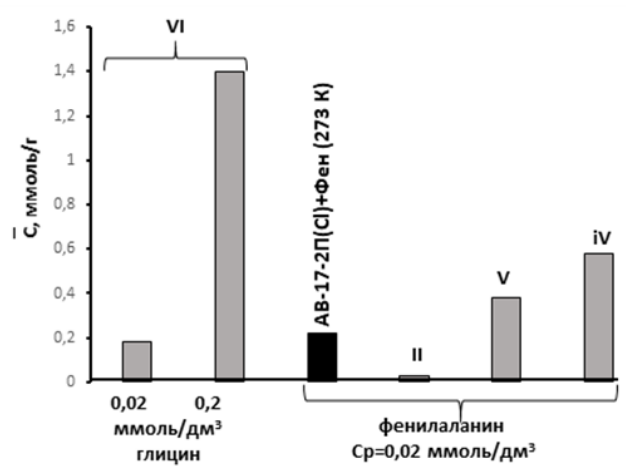

Рис.2. Величина сорбции аминокислот в исследуемых системах при концентрации равновесного раствора

$$
\text { Ср } \sim 0.02 \text { моль/дм }{ }^{3}
$$

(и 0.2 моль/дм ${ }^{3}$ для глицина)

Fig. 2. The value of sorption of amino acids in the studied systems at the concentration of the equilibrium solution $\mathrm{Cp} \sim 0.02 \mathrm{~mol} / \mathrm{dm}^{3}$ (and $0.2 \mathrm{~mol} / \mathrm{dm}^{3}$ for glycine)

Известно [7, 8], что увеличение концентрации вещества в растворе приводит к росту концентрации в сорбенте. При этом даже вещества, относящиеся к одному и тому же классу, могут иметь значительно различающуюся растворимость, а, следовательно, рабочий диапазон концентраций. К таким веществам относятся и аминокислоты - их гидрофобные представители наименее растворимы в воде по сравнению с другими цвиттерлитами [9]. На рис. 3 представлены изотермы сорбции фенилаланина и глицина АВ-17-2П в хлоридной ионной форме в области концентраций, ограниченных растворимостью аминокислот.

Как видно из рис. 3, изотермы сорбции аминокислот при одинаковых концентрациях практически совпадают, что обусловлено протеканием полярных взаимодействий в фазе сорбента. При повышении концентрации эффект увеличения сорбции глицина за счет высокой растворимости значительно больше эффекта от нарастания роли гидрофобных

\section{Список литературы}

1. Хохлова О.Н., Каширцева Е.Р., Хохлов В.Ю., Трунаева Е.С. // Журнал физической химии. 2021. Т. 95. № 4. С. 581-587

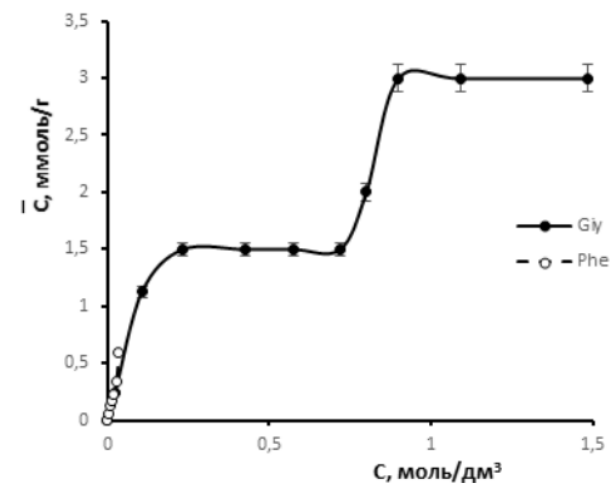

Рис. 3. Сравнение изотерм сорбции глицина и фенилаланина в пределах растворимости каждой из аминокислот Fig. 3. Comparison of sorption isotherms of glycine and phenylalanine within the solubility limits of each of the amino acids

взаимодействий при сорбции фенилаланина. Поглощение глицина при высоких концентрациях раствора приводит к формированию в сорбенте последовательно первого и второго слоя вещества на сорбционных центрах сорбента.

\section{Заключение}

Таким образом, из рассмотренных факторов наибольшее действие на величину поглощения аминокислот при необменной сорбции оказывает концентрационный фактор. Изменение свойств одного из компонентов системы значимо оказывает влияние на равновесие сорбции при изменении на порядок. Роль растворителя при необменной сорбции аминокислот косвенно проявляется при рассмотрении прочих действующих факторов в системе из-за участия в полярных взаимодействиях сорбата и сорбента.

2. Трунаева Е.С., Хохлова О.Н., Хохлов В.Ю. // Сорбционные и хроматографические проиессы. 2018. Т. 18. Вып. 2. С. 142-149.

3. Bowden N.A., Johan P.M. Sanders, Bruins M.E. // Journal of Chemical \& Engineering. 2018. № 63. p. 488-497. 
4. Хохлов В.Ю., Селеменев В.Ф., Хохлова О.Н., Загородний А.А. // Вестник ВГУ. Серия химия, биология, фармачия. 2003. № 1. C. $18-22$.

5. Dougherty R.C. // J. Chem. Phys. 1998. Vol. 109. p. 7372.

6. Schellman J.A. // Biophys J. 1997. Vol. 73. No 6. pp. 2960-2964.
7. Гельферих, Ф. Иониты. М. Издательство иностранной литературы. 1962. 490 с.

8. Крачак А.Н., Хамизов Р.Х., Долгоносов А.М., Малыкова Л.М. // Сорбционные и хроматографические проиессы. 2014. Т. 14. № 6. С. 902-911.

9. Справочник биохимика. Пер. с англ. Доссон Р., Эллиот Д., Эллиот У., Джонс К. М. Мир. 1991. 544 с.

\title{
Influence of various factors on the non-exchange sorption of amino acids by anion exchangers
}

\author{
(C) 2021 Khokhlova O.N., Troshina P.V., Bykovskaya A.I., \\ Kashirtseva E.R., Khokhlov V.Yu. \\ Voronezh State University, Voronezh
}

\begin{abstract}
In order to review a number of factors involved in the non-exchange sorption of amino acids by ion exchangers, we studied the influence of the nature and ionic form of the sorbent, sorbate, and solvent and the sorption conditions (the temperature and the concentration range) on the absorption of glycine and phenylalanine by an AV-17-2P anion exchanger and a MN-150 hypercross-linked sorbent from aqueous and alcoholic solutions at temperatures of 293 and $343 \mathrm{~K}$ within the concentration ranges limited by the solubility of amino acids.

It was established that a change in the ionic form of the AV-17-2P anion exchanger from chloride to nitrate results in a decrease in the amount of absorbed phenylalanine. This is due to changes in the dimensional and hydration characteristics of the counterion which lead to a weakening of polar interactions in the sorbent phase and non-exchange attachment of amino acids. Using non-aqueous solvent, for example, ethyl alcohol, results in a decrease in the solubility of amino acids, and, therefore, in the working range of concentrations, and a decrease in ion exchanger swelling. As a result, a smaller amount of amino acid was absorbed.

Using a hypercross-linked sorbent or an increase in temperature led to a significant improvement in the phenylalanine absorption. In the former case, the hydrophobic interactions between the aromatic group of phenylalanine and the sorbent matrix were enhanced. In the latter case, the multidirectional effect of the temperature factor on the sorbate, sorbent, and the bonds between them ultimately led to an increase in sorption due to improved swelling of the ion exchanger.

The good solubility of glycine allows studying the absorption of this amino acid over a wide range of concentrations. The type of the obtained isotherm and the consideration of the characteristics of the ion exchanger allowed establishing that the first and second layers of the substance were successively formed on the sorption centres "functional group-counterion" in the sorbent.
\end{abstract}

Keywords: anion exchanger, glycine, phenylalanine, non-exchange sorption.

\section{References}

1. Khokhlova O.N., Kashirtseva E.R., Khokhlov V.Yu., Trynaeva E.S., Russian Journal of Physical Chemistry A, 2021, Vol. 95, No 4, pp. 762-768.

2. Trynaeva E.S., Khokhlova O.N., Khokhlov V.Yu., Sorbtsionnye $i$ khromatograficheskie protsessy, 2018, Vol. 18, No 2, pp. 142-149.

3. Bowden N.A., Johan P.M. Sanders, Bruins M.E., Journal of Chemical \& Engineering, 2018, No 63, pp. 488-497.
4. Khokhlov V.Yu., Selemenev V.F., Khokhlova O.N., Zagorodny A.A., Vestnik VGU. Seriya:Khimiya, Biologiya, Pharmatsiya, 2003, No 1, pp. 18-22.

5. Dougherty R.C., J. Chem. Phys., 1998, Vol. 109, pp. 7372. https://doi.org/10.1063/ 1.477343

6. Schellman J.A., Biophys J., 1997, Vol. 73, No 6, pp. 2960-2964. doi: 10.1016/S00063495(97)78324-3

7. Gelferikh F., Ionity: Osnovy ionnogo obmena. M., Izd-vo inostr. lit-ry, 1962, 490 p. 
8. Krachak A.N., Khamizov R.H., Dolgonosov A.M., Malykova L.M., Sorbtsionnye $i$ khromatograficheskie protsessy, 2014, Vol. 14, No 6, pp. 902-911.

Хохлова Оксана Николаевна - к.х.н., доцент кафедры аналитической химии, химический факультет, Воронежский Государственный Университет, Воронеж

Хохлов Владимир Юрьевич - д.Х.н., профессор кафедры аналитической химии, химический факультет, Воронежский Государственный Университет, Воронеж.

Трошина Полина Владимировна - студент кафедры аналитической химии, химический факультет, Воронежский Государственный Университет, Воронеж

Быковская Алина Ивановна - студент кафедры аналитической химии, химический факультет, Воронежский Государственный Университет, Воронеж

Каширцева Елизавета Романовна - аспирант кафедры аналитической химии, химический факультет, Воронежский Государственный Университет, Воронеж
9. Dawson R.M.C., Elliott W.H., Elliott D.C., Jones K.M., Data for Biochemical Research, 1989, $592 \mathrm{p}$.

Khokhlova Oksana N. - associate professor, department of analytical chemistry, chemical faculty, Voronezh State University, Voronezh, e-mail: okxox@yandex.ru

Khokhlov Vladimir Yu. - professor, department of analytical chemistry, chemical faculty, Voronezh State University, Voronezh, e-mail: vladkh70@mail.ru

Troshina Polina V. - student, department of analytical chemistry, chemical faculty, Voronezh State University, Voronezh, e-mail: poly.troshina@yandex.ru

Bykovskaya Alina I. - student, department of analytical chemistry, chemical faculty, Voronezh State University, $\quad$ Voronezh, lina.bykovskaya@mail.ru

Kashirtseva Elizaveta R. - postgraduate, department of analytical chemistry, chemical faculty, Voronezh State University, Voronezh, e-mail: kashirtseva_e@mail.ru 